\title{
Preventing vasospasm improves outcome after aneurysmal subarachnoid hemorrhage: rationale and design of CONSCIOUS- 2 and CONSCIOUS- 3 trials
}

Macdonald, R L; Higashida, R; Keller, E; Mayer, S A; Molyneux, A; Raabe, A; Vajkoczy, P; Wanke, I; Bach, D; Frey, A; Marr, A; Roux, S; Kassel, N

Macdonald, R L; Higashida, R; Keller, E; Mayer, S A; Molyneux, A; Raabe, A; Vajkoczy, P; Wanke, I; Bach, D; Frey, A; Marr, A; Roux, S; Kassel, N (2011). Preventing vasospasm improves outcome after aneurysmal subarachnoid hemorrhage: rationale and design of CONSCIOUS- 2 and CONSCIOUS-3 trials. Neurocritical Care, 13(3):416-424.

Postprint available at:

http://www.zora.uzh.ch

Posted at the Zurich Open Repository and Archive, University of Zurich.

http://www.zora.uzh.ch

Originally published at:

Macdonald, R L; Higashida, R; Keller, E; Mayer, S A; Molyneux, A; Raabe, A; Vajkoczy, P; Wanke, I; Bach, D; Frey, A; Marr, A; Roux, S; Kassel, N (2011). Preventing vasospasm improves outcome after aneurysmal subarachnoid hemorrhage: rationale and design of CONSCIOUS-2 and CONSCIOUS-3 trials. Neurocritical Care, 13(3):416-424. 


\title{
Preventing vasospasm improves outcome after aneurysmal subarachnoid hemorrhage: rationale and design of CONSCIOUS- 2 and CONSCIOUS-3 trials
}

\begin{abstract}
Cerebral vasospasm after aneurysmal subarachnoid hemorrhage (aSAH) is a frequent but unpredictable complication associated with poor outcome. Current vasospasm therapies are suboptimal; new therapies are needed. Clazosentan, an endothelin receptor antagonist, has shown promise in phase 2 studies, and two randomized, double-blind, placebo-controlled phase 3 trials (CONSCIOUS-2 and CONSCIOUS-3) are underway to further investigate its impact on vasospasm-related outcome after aSAH. Here we describe the design of these studies, which was challenging with respect to defining endpoints and standardizing endpoint interpretation and patient care. Main inclusion criteria are: age 18-75 years; SAH due to ruptured saccular aneurysm secured by surgical clipping (CONSCIOUS-2) or endovascular coiling (CONSCIOUS-3); substantial subarachnoid clot; and World Federation of Neurosurgical Societies grades I-IV prior to aneurysm-securing procedure. In CONSCIOUS-2, patients are randomized 2:1 to clazosentan $(5 \mathrm{mg} / \mathrm{h})$ or placebo. In CONSCIOUS-3, patients are randomized 1:1:1 to clazosentan $5 \mathrm{mg} / \mathrm{h}, 15 \mathrm{mg} / \mathrm{h}$ or placebo. Treatment is initiated within $56 \mathrm{~h}$ of aSAH and continued until 14 days after aSAH. Primary endpoint is a composite of mortality and vasospasm-related morbidity within 6 weeks of aSAH (all-cause mortality, vasospasm-related new cerebral infarction, vasospasm-related delayed ischemic neurological deficit, neurological signs or symptoms in the presence of angiographic vasospasm leading to rescue therapy initiation). Main secondary endpoint is extended Glasgow Outcome Scale (GOSE) at week 12. A critical events committee assesses all data centrally to ensure consistency in interpretation, and patient management guidelines are used to standardize care. Results are expected at the end of 2010 and 2011 for CONSCIOUS-2 and CONSCIOUS-3, respectively.

Introduction Advances have been made in the management of patients with aneurysmal subarachnoid hemorrhage (aSAH). Mortality among those who reach hospital alive has decreased $0.9 \%$ per year since 1980 [1]. Nevertheless, case fatality is still $40 \%$ and half of all survivors suffer some form of physical, emotional or cognitive impairment [2-4]. The causes of morbidity and mortality are mainly initial effects of the aSAH and delayed ischemic neurological deficit (DIND), which is usually due to cerebral vasospasm [5]. Indeed, vasospasm is considered to be one of the main preventable causes of morbidity and mortality [6]. Angiographic vasospasm (vasospasm that is visible on an angiogram) occurs in up to $70 \%$ of patients after aSAH [6]; DIND has been estimated to account for $50 \%$ of deaths in people surviving the initial SAH [7]. Current management options for the prevention and treatment of vasospasm and DIND include hemodynamic therapy, nimodipine, fasudil (in Japan), intra-arterial vasodilators and angioplasty, but none are very effective [7-12]. Clazosentan is an endothelin receptor antagonist under investigation for the prevention of vasospasm and subsequent morbidity and mortality. A phase 2a proof-of-principle trial administered $0.2 \mathrm{mg} / \mathrm{kg} / \mathrm{h}$ clazosentan (corresponding to $15 \mathrm{mg} / \mathrm{h}$ for an individual weighing $75 \mathrm{~kg}$ ) beginning within $48 \mathrm{~h}$ of the aneurysm securing procedure and continuing until Day 14 after aSAH. Clazosentan reduced moderate/severe angiographic vasospasm by $55 \%$ relative to placebo (angiographic vasospasm was observed in $88 \%$ and $40 \%$ of placebo- and clazosentan-treated patients, respectively, $\mathrm{P}=0.008$ ) [13]. These results supported conduct of a dose-finding safety trial (Clazosentan to Overcome Neurological iSChemia and Infarct OccUrring after Subarachnoid hemorrhage CONSCIOUS-1; phase 2b]). The primary outcome was angiographic vasospasm. The sample size was estimated from the effect on angiographic vasospasm in the phase 2a trial and the doses selected based on the phase 2a trial and also phase 1 clinical trials administering clazosentan to healthy volunteers and observing clinical and cardiovascular effects $[13,14]$.
\end{abstract}


CONSCIOUS-1 recruited 413 patients from 11 countries [15]. Patients were randomized to intravenous clazosentan $(1,5$ or $15 \mathrm{mg} / \mathrm{h}$ ) or placebo, beginning within $56 \mathrm{~h}$ of aSAH and continuing until Day 14 after aneurysm rupture. Clazosentan significantly and dose-dependently reduced moderate/severe angiographic vasospasm relative to placebo; the highest dose $(15 \mathrm{mg} / \mathrm{h})$ led to a $65 \%$ risk reduction $(\mathrm{P}<$ 0.0001) [15]. CONSCIOUS-1 was not powered to detect a change in morbidity, mortality or patient-centered clinical outcome, but has been repeatedly and incorrectly cited as evidence that angiographic vasospasm does not contribute to poor outcome after aSAH [16]. This idea was put forth at least 35 years ago, but the basis remains as speculative now as it was then [17]. Post hoc, central analysis of all-cause mortality and vasospasm-related morbidity in CONSCIOUS-1 found a trend towards improved outcomes with clazosentan [15]. Two large, multinational phase 3 studies, CONSCIOUS- 2 and CONSCIOUS-3, have now been initiated, based on the results of the CONSCIOUS-1 trial, to further investigate the effect of clazosentan on outcome after aSAH. This manuscript describes the rationale for the design and methodology of these studies. Methods Study design CONSCIOUS-2 and CONSCIOUS-3 are prospective, multinational, double-blind, placebo-controlled studies. The primary objective is to determine if clazosentan decreases vasospasm-related morbidity and all-cause mortality in patients with aSAH. Patients are randomized within $56 \mathrm{~h}$ of aSAH to intravenous clazosentan $(5 \mathrm{mg} / \mathrm{h}$ in CONSCIOUS-2; 5 or $15 \mathrm{mg} / \mathrm{h}$ in CONSCIOUS-3) or placebo administered until Day 14 after aSAH, with a post-aSAH follow-up period of up to 12 weeks (Figure 1). Randomization is by an independent contract research organization using an interactive web response system, which assigns a randomization number according to a predefined randomization scheme. Randomization is stratified by site. In both studies, patients are managed according to procedures for aSAH at the study center (i.e., study drug is added to usual care) although patient management guidelines have been implemented (see below) to standardize care between centers. Drugs or procedures that are not standard care are forbidden including intravenous magnesium or statins when prescribed for the prevention of cerebral vasospasm, thrombolytics and antifibrinolytics, hypertonic saline without hyponatremia or increased intracranial pressure, calcineurin inhibitors, and endothelin receptor antagonists other than the study drug. Oral nimodipine is permitted, but not intravenous nimodipine or intravenous nicardipine. The study protocols are approved by local institutional review boards. The trials are registered on clinicaltrials.gov: registration numbers: NCT00558311 (CONSCIOUS-2) and NCT00940095 (CONSCIOUS-3). CONSCIOUS-2 enrolled 1157 patients in 102 centers in 27 countries; CONSCIOUS-3 is expected to enroll more than 1400 patients in approximately 150 centers in more than 25 countries. The rationale for separate studies of clipped and coiled patients was based on CONSCIOUS-1 analyses, indicating differences in endpoint occurrence when patients were stratified by securing procedure. Specifically, in CONSCIOUS-1 patients secured by clipping, the incidence of the composite endpoint in the placebo group was $45 \%$ compared with $46 \%$, $25 \%$ and $40 \%$ in $1 \mathrm{mg} / \mathrm{h}, 5 \mathrm{mg} / \mathrm{h}$ and $15 \mathrm{mg} / \mathrm{h}$ groups, respectively. In contrast, in patients secured by coiling, the incidence of the composite endpoint in the placebo group was lower at $34 \%$ compared with $31 \%, 32 \%$ and $20 \%$ in $1 \mathrm{mg} / \mathrm{h}, 5 \mathrm{mg} / \mathrm{h}$ and $15 \mathrm{mg} / \mathrm{h}$ groups, respectively. Furthermore, an exploratory, retrospective analysis of CONSCIOUS-1 data showed that, relative to coiled patients, clipped patients had significantly higher rates of angiographic vasospasm (36\% vs. 55\%, respectively) and DIND (15\% and $23 \%$, respectively) [18]. Together these observations supported the conduct of separate trials for clipped and coiled patients and suggested that while the $5 \mathrm{mg} / \mathrm{h}$ dose might be most appropriate for clipped patients a potentially higher dose was additionally worth investigating in coiled patients. 


\section{Preventing vasospasm improves outcome after aneurysmal subarachnoid hemorrhage: rationale and design of CONSCIOUS-2 and CONSCIOUS-3 trials}

\section{Authors:}

- R. Loch Macdonald, M.D., Ph.D., Division of Neurosurgery, St. Michael's Hospital, Labatt Family Centre of Excellence in Brain Injury and Trauma Research, Keenan Research Centre of the Li Ka Shing Knowledge Institute of St. Michael's and Department of Surgery, University of Toronto, Toronto, Canada

- Randall T. Higashida, M.D., Division of Neurointerventional Radiology, University of California, San Francisco Medical Center, San Francisco, CA, USA

- Emanuela Keller, M.D., Universitätsspital Zürich, Neurochirurgische Klinik, Zürich, Switzerland

- Stephan A. Mayer, M.D., Department of Neurology, Columbia University, New York, NY, USA

- Andy Molyneux, M.D., Nuffield Department of Surgery, John Radcliffe Hospital, Oxford, UK

- Andreas Raabe, M.D., Inselspital Bern, Universitätsklinik für Neurochirurgie, Bern, Switzerland

- Peter Vajkoczy, M.D., Department of Neurosurgery, Charitie Universitätsmedizin Berlin, Berlin, Germany

- Isabel Wanke, M.D., Clinic Hirslanden, Zurich, Switzerland

- Aline Frey, PharmD, Actelion Pharmaceuticals Ltd, Allschwil, Switzerland

- Angelina Marr, BSc Pharm, Actelion Pharmaceuticals Ltd, Allschwil, Switzerland

- Sébastien Roux, M.D., Actelion Pharmaceuticals Ltd, Allschwil, Switzerland

- Neal F. Kassell, M.D., Department of Neurosurgery, University of Virginia, Charlottesville, VA, USA 


\section{Corresponding author:}

R. Loch Macdonald, M.D., Ph.D.

Keenan Endowed Chair in Surgery

Head, Division of Neurosurgery

St. Michael's Hospital

Professor of Surgery, University of Toronto

30 Bond Street

Toronto, Ontario, Canada M5B 1W8

Phone: +1 (416) 8645393

Fax: +1 (416) 8645634

Email:macdonaldlo@smh.ca

Target journal: Neurocritical Care

Key words: aneurysmal subarachnoid hemorrhage; cerebral vasospasm; clazosentan; CONSCIOUS studies; clinical outcome

Running head: CONSCIOUS-2 and -3 study design: clazosentan and clinical outcome Word count: 3307 (body text, excluding acknowledgements, disclosures, references, figure legends and table titles) 


\section{Abstract}

Cerebral vasospasm after aneurysmal subarachnoid hemorrhage (aSAH) is a frequent but unpredictable complication associated with poor outcome. Current vasospasm therapies are suboptimal; new therapies are needed. Clazosentan, an endothelin receptor antagonist, has shown promise in phase 2 studies, and two randomized, double-blind, placebo-controlled phase 3 trials (CONSCIOUS-2 and CONSCIOUS-3) are underway to further investigate its impact on vasospasm-related outcome after aSAH. Here we describe the design of these studies, which was challenging with respect to defining endpoints and standardizing endpoint interpretation and patient care. Main inclusion criteria are: age $18-75$ years; SAH due to ruptured saccular aneurysm secured by surgical clipping (CONSCIOUS-2) or endovascular coiling (CONSCIOUS-3); substantial subarachnoid clot; and World Federation of Neurosurgical Societies grades I-IV prior to aneurysm-securing procedure. In

CONSCIOUS-2, patients are randomized 2:1 to clazosentan $(5 \mathrm{mg} / \mathrm{h})$ or placebo. In CONSCIOUS-3, patients are randomized $1: 1: 1$ to clazosentan $5 \mathrm{mg} / \mathrm{h}, 15 \mathrm{mg} / \mathrm{h}$ or placebo. Treatment is initiated within $56 \mathrm{~h}$ of aSAH and continued until 14 days after aSAH. Primary endpoint is a composite of mortality and vasospasm-related morbidity within 6 weeks of aSAH (all-cause mortality, vasospasm-related new cerebral infarction, vasospasm-related delayed ischemic neurological deficit, neurological signs or symptoms in the presence of angiographic vasospasm leading to rescue therapy initiation). Main secondary endpoint is extended Glasgow Outcome Scale (GOSE) at week 12. A critical events committee assesses all data centrally to ensure consistency in interpretation, and patient management guidelines are used to standardize care. Results are expected at the end of 2010 and 2011 for CONSCIOUS-2 and CONSCIOUS-3, respectively. 


\section{Introduction}

Advances have been made in the management of patients with aneurysmal subarachnoid hemorrhage (aSAH). Mortality among those who reach hospital alive has decreased $0.9 \%$ per year since 1980 [1]. Nevertheless, case fatality is still $40 \%$ and half of all survivors suffer some form of physical, emotional or cognitive impairment [2-4]. The causes of morbidity and mortality are mainly initial effects of the aSAH and delayed ischemic neurological deficit (DIND), which is usually due to cerebral vasospasm [5]. Indeed, vasospasm is considered to be one of the main preventable causes of morbidity and mortality [6]. Angiographic vasospasm (vasospasm that is visible on an angiogram) occurs in up to $70 \%$ of patients after aSAH [6]; DIND has been estimated to account for $50 \%$ of deaths in people surviving the initial SAH [7].

Current management options for the prevention and treatment of vasospasm and DIND include hemodynamic therapy, nimodipine, fasudil (in Japan), intra-arterial vasodilators and angioplasty, but none are very effective [7-12]. Clazosentan is an endothelin receptor antagonist under investigation for the prevention of vasospasm and subsequent morbidity and mortality. A phase 2a proof-of-principle trial administered $0.2 \mathrm{mg} / \mathrm{kg} / \mathrm{h}$ clazosentan (corresponding to $15 \mathrm{mg} / \mathrm{h}$ for an individual weighing $75 \mathrm{~kg}$ ) beginning within $48 \mathrm{~h}$ of the aneurysm securing procedure and continuing until Day 14 after aSAH. Clazosentan reduced moderate/severe angiographic vasospasm by $55 \%$ relative to placebo (angiographic vasospasm was observed in $88 \%$ and $40 \%$ of placebo- and clazosentan-treated patients, respectively, $P=0.008)[13]$.

These results supported conduct of a dose-finding safety trial (Clazosentan to Overcome Neurological iSChemia and Infarct OccUrring after Subarachnoid hemorrhage CONSCIOUS1; phase 2b]). The primary outcome was angiographic vasospasm. The sample size was estimated from the effect on angiographic vasospasm in the phase $2 a$ trial and the doses selected based on the phase $2 a$ trial and also phase 1 clinical trials administering 
clazosentan to healthy volunteers and observing clinical and cardiovascular effects $[13,14]$. CONSCIOUS-1 recruited 413 patients from 11 countries [15]. Patients were randomized to intravenous clazosentan $(1,5$ or $15 \mathrm{mg} / \mathrm{h})$ or placebo, beginning within $56 \mathrm{~h}$ of aSAH and continuing until Day 14 after aneurysm rupture. Clazosentan significantly and dosedependently reduced moderate/severe angiographic vasospasm relative to placebo; the highest dose $(15 \mathrm{mg} / \mathrm{h})$ led to a $65 \%$ risk reduction $(P<0.0001)$ [15]. CONSCIOUS-1 was not powered to detect a change in morbidity, mortality or patient-centered clinical outcome, but has been repeatedly and incorrectly cited as evidence that angiographic vasospasm does not contribute to poor outcome after aSAH [16]. This idea was put forth at least 35 years ago, but the basis remains as speculative now as it was then [17]. Post hoc, central analysis of all-cause mortality and vasospasm-related morbidity in CONSCIOUS-1 found a trend towards improved outcomes with clazosentan [15].

Two large, multinational phase 3 studies, CONSCIOUS-2 and CONSCIOUS-3, have now been initiated, based on the results of the CONSCIOUS-1 trial, to further investigate the effect of clazosentan on outcome after aSAH. This manuscript describes the rationale for the design and methodology of these studies.

\section{Methods}

Study design

CONSCIOUS-2 and CONSCIOUS-3 are prospective, multinational, double-blind, placebocontrolled studies. The primary objective is to determine if clazosentan decreases vasospasm-related morbidity and all-cause mortality in patients with aSAH. Patients are randomized within $56 \mathrm{~h}$ of aSAH to intravenous clazosentan $(5 \mathrm{mg} / \mathrm{h}$ in CONSCIOUS-2; 5 or $15 \mathrm{mg} / \mathrm{h}$ in CONSCIOUS-3) or placebo administered until Day 14 after aSAH, with a postaSAH follow-up period of up to 12 weeks (Figure 1). Randomization is by an independent contract research organization using an interactive web response system, which assigns a 
randomization number according to a predefined randomization scheme. Randomization is stratified by site.

In both studies, patients are managed according to procedures for aSAH at the study center (i.e., study drug is added to usual care) although patient management guidelines have been implemented (see below) to standardize care between centers. Drugs or procedures that are not standard care are forbidden including intravenous magnesium or statins when prescribed for the prevention of cerebral vasospasm, thrombolytics and antifibrinolytics, hypertonic saline without hyponatremia or increased intracranial pressure, calcineurin inhibitors, and endothelin receptor antagonists other than the study drug. Oral nimodipine is permitted, but not intravenous nimodipine or intravenous nicardipine. The study protocols are approved by local institutional review boards. The trials are registered on clinicaltrials.gov: registration numbers: NCT00558311 (CONSCIOUS-2) and NCT00940095 (CONSCIOUS-3). CONSCIOUS-2 enrolled 1157 patients in 102 centers in 27 countries; CONSCIOUS-3 is expected to enroll more than 1400 patients in approximately 150 centers in more than 25 countries.

The rationale for separate studies of clipped and coiled patients was based on CONSCIOUS-1 analyses, indicating differences in endpoint occurrence when patients were stratified by securing procedure. Specifically, in CONSCIOUS-1 patients secured by clipping, the incidence of the composite endpoint in the placebo group was $45 \%$ compared with $46 \%$, $25 \%$ and $40 \%$ in $1 \mathrm{mg} / \mathrm{h}, 5 \mathrm{mg} / \mathrm{h}$ and $15 \mathrm{mg} / \mathrm{h}$ groups, respectively. In contrast, in patients secured by coiling, the incidence of the composite endpoint in the placebo group was lower at $34 \%$ compared with $31 \%, 32 \%$ and $20 \%$ in $1 \mathrm{mg} / \mathrm{h}, 5 \mathrm{mg} / \mathrm{h}$ and $15 \mathrm{mg} / \mathrm{h}$ groups, respectively. Furthermore, an exploratory, retrospective analysis of CONSCIOUS-1 data showed that, relative to coiled patients, clipped patients had significantly higher rates of angiographic vasospasm (36\% vs. $55 \%$, respectively) and DIND (15\% and $23 \%$, respectively) [18]. Together these observations supported the conduct of separate trials for 
clipped and coiled patients and suggested that while the $5 \mathrm{mg} / \mathrm{h}$ dose might be most appropriate for clipped patients a potentially higher dose was additionally worth investigating in coiled patients.

\section{Patient population}

Inclusion and exclusion criteria were selected to enrich the population for vasospasm and to exclude patients with poor prognosis who have high mortality before the development of vasospasm. Inclusion criteria are: age 18-75 years, SAH due to ruptured saccular aneurysm, and World Federation of Neurological Societies (WFNS) grades I-IV prior to securing procedure (WFNS grade $\mathrm{V}$ patients are excluded due to high early mortality rate). Exclusion criteria include SAH due to non-aneurysmal causes, intraventricular or intracerebral hemorrhage without subarachnoid blood, the presence of vasospasm on screening angiogram and major complications during the aneurysm-securing procedure. Entry into CONSCIOUS-2 requires a diffuse clot on the admission computed tomographic (CT) scan (long axis $\geq 20 \mathrm{~mm}$ or present in both hemispheres) and an aneurysm secured through surgical clipping. CONSCIOUS-3 requires a thick clot (short axis $\geq 4 \mathrm{~mm}$ ) and an aneurysm secured by endovascular coiling. This requirement for a large or thick clot excludes patients with minimal subarachnoid blood, who are less likely to experience vasospasm. In both studies, randomization occurred after securing procedure, thus patients sustaining a major complication during the securing procedure, such as massive bleeding, major arterial occlusion, large territorial cerebral infarct defined as involving $>1 / 3$ of a vascular territory, or new major neurological deficit postprocedure (e.g., hemiplegia or aphasia lasting $\geq 12 \mathrm{~h}$ post-aneurysm securing) are excluded. Written informed consent is obtained in accordance with the local EC/IRB regulations. 
Study assessments

At baseline, prior to the aneurysm securing procedure, all patients undergo a CT scan and catheter or CT angiography. Additional CT scans are performed $24-48 \mathrm{~h}$ after the securing procedure, at discharge, 6 weeks after aneurysm rupture, and in cases of worsening neurological condition. Additional CT or catheter angiograms are performed after endovascular treatment (CONSCIOUS-3 only) to document the completeness of the aneurysm occlusion, if symptoms suggestive of cerebral vasospasm or suspicion of cerebral infarct occur, and in the case of worsening neurological condition. After study drug initiation, neurological assessments using the modified Glasgow Coma Scale (mGCS) and the abbreviated National Institutes of Health Stroke Scale (NIHSS) are performed every $6 \mathrm{~h}$ until Day 14. Patients return to the investigational site for a follow-up visit 6 weeks after SAH. At Week 12 , specially trained centralized interviewers conduct a structured telephone interview to obtain scores for the Glasgow Outcome Scale (extended version, GOSE $[19,20]$ ), and modified Rankin Scale [21,22]. During this interview, a brief (11-item) standardized evaluation of cognitive functioning (Telephone Interview for Cognitive Status [3,23]) is also performed.

\section{Endpoints}

The primary and secondary endpoints for both studies are summarized in Table 1 . The primary endpoint is a composite including mortality as well as vasospasm-related cerebral infarction, vasospasm-related DIND and vasospasm-related neurological signs and symptoms leading to use of a valid rescue therapy. Unlike diseases such as diabetes and cancer, where formal guidelines identify appropriate endpoints for assessing safety and efficacy [24], there are none for aSAH. The selection of the primary endpoint was based on several factors. First, it is similar to that used in the only positive clinical trial of medical treatment for aSAH [25]. Second, all of the components are clinically relevant: cerebral 
infarction is one of the most powerful prognostic factors associated with poor outcome after aSAH, DIND is highly associated with cerebral infarction $[26,27]$ and rescue therapy to treat DIND is costly. Finally, it is important that the endpoint assesses outcomes that are likely to be influenced by a reduction in vasospasm, as this is the mode of action of clazosentan. Cerebral infarction and DIND have been associated with vasospasm. For example, Weidauer et al [28] reported that $53 \%$ of patients experienced new infarcts within 28 days of aSAH, and that $81 \%$ of these were related to severe cerebral vasospasm. Furthermore, approximately $50 \%$ of patients with vasospasm will experience DIND [7] and, while Dankbaar et al [29] reported that vasospasm does not always cause delayed ischemia, they did find that patients with severe vasospasm more often experienced delayed cerebral ischemia than those without. The focus on vasospasm-related endpoints is also justified because vasospasm is a major preventable cause of poor outcome. There are multiple causes of morbidity in patients initially surviving after aSAH, including the initial hemorrhage (e.g., extent of bleed), which is not modifiable; surgery-related injury (e.g., retraction or perforator injury); and peri-operative morbidity such as hydrocephalus, cardiopulmonary complications, metabolic and fluid-related complications which may be managed to a degree but cannot always be prevented.

In CONSCIOUS-2 and CONSCIOUS-3, DIND is defined as a decrease of at least two points on the mGCS or an increase of at least two points on the abbreviated NIHSS (Table 2) lasting for at least $2 \mathrm{~h}$. For patients who require continuous sedation, when possible sedation is interrupted at least once daily to allow for neurological assessment. If a patient is not assessable, DIND is defined as administration of a valid rescue therapy for a justifiable reason. Rescue therapies include initiation or increase in dose of an intravenous vasopressor with or without fluid therapy, or intra-arterial vasodilator or balloon angioplasty. Vasospasm is defined as narrowing of at least one third of the diameter of the large intracranial arteries. 
The main secondary endpoint is GOSE. GOSE was not the primary endpoint due to prohibitively large sample size estimates [30]. Additionally, outcome scales, such as GOSE, are not always sensitive to change, particularly when dichotomized (e.g., poor/good outcome) [31], and there may be confounders in the interpretation of these scales. For example, GOSE uses a categorical scale to assess major social roles (activities of independent living, work, leisure, personal relationships) which may be confounded by patient age, inter-individual variation in neuroplasticity and recovery capacity, and the degree of family and community social support [32]. Moreover, classical outcome scales do not address cognitive impairment, which is frequent after aSAH [3]. Together, these factors mean GOSE is more appropriate as a secondary rather than primary endpoint.

Safety endpoints include death up to week 12 post-aSAH; treatment-emergent adverse events (including those of special interest, e.g., lung complications, hypotension, anemia, cerebral hemorrhage, cardiovascular and eye disorders); adverse events leading to premature drug discontinuation; serious adverse events up to 28 days after drug discontinuation; new or worsened cerebral infarcts (all etiologies) up to Week 6 post-aSAH; and laboratory parameters.

\section{Centralized Critical Events Committee}

In CONSCIOUS-1, investigator assessment of ischemic morbidity led to a different pattern of results than a post hoc blinded assessment of the same data by a central review committee (Figure 2 [15]). For example, in some cases, investigators attributed DIND to vasospasm when central review of angiograms did not show vasospasm. Hypodensities on CT scans were sometimes attributed to vasospasm when there was no vasospasm on angiography, or when the hypodensities were already present on the CT scan 24 to $48 \mathrm{~h}$ after the aneurysmsecuring procedure and were therefore judged centrally to be due to the aneurysm-securing procedure or other peri-procedural events. For this reason, CONSCIOUS-2 and 
CONSCIOUS-3 use a centralized critical events committee comprising neurointensivists, neurosurgeons and neuroradiologists to evaluate images and other clinical data from the individual centers. Centralized assessment (rather than investigator opinion) has been used in many randomized clinical trials to ensure that data are consistent and as closely reflective of reality as possible [25].

This committee comprises an image review subcommittee of neuroradiologists and a clinical review subcommittee of neurosurgeons and neurointensivists. Based on review of CT and catheter angiograms, the image review committee determines if angiographic vasospasm is present. If a new hypodensity on a CT scan is classified as a cerebral infarction, the committee determines its location, volume and etiology. In the absence of an angiogram concomitant to a neurological worsening episode, the committee determines the etiology of new hypodensities based on best judgment. For instance, a new hypodensity located in a large artery or watershed territory would usually be attributed to angiographic vasospasm. In contrast, procedure-related infarcts are defined as those appearing within 2 days of surgery, in a vascular territory, and attributable to artery occlusion or injury. Hypodensity underlying a thick clot, or due to intraparenchymal hemorrhage, an external ventricular drain or small hypodensities secondary to retraction injury due to the surgical approach are considered encephalomalacia and not infarction. Hypodensity of unknown etiology is considered infarction. The clinical review committee is composed of a pool of nine experts (six neurosurgeons and three neurointensivists). Each patient is reviewed in an independent manner by three reviewers (two neurosurgeons and one neurointensivist) who make a final assessment of the individual components of the primary endpoint (cerebral infarction, DIND or the administration of rescue therapy and their causes [cerebral vasospasm-related or not]). The review is performed through a web-based system giving access to patient clinical data as well as study-specific brain images. Unanimity is required. In case of disagreement on one or more of the components of the primary endpoint, the initial reviewers discuss the case in a consensus meeting. If consensus cannot be reached, the case is adjudicated by 
an additional reviewer (either the Chair of the committee or an intensivist not among the initial reviewers).

\section{Patient management guidelines}

In CONSCIOUS-1, clazosentan use was associated with lung complications (including pulmonary edema, acute respiratory distress syndrome, pleural effusion and pneumonia), anemia and hypotension. The occurrence of lung complications was associated with positive fluid balance. Kramer and Fletcher [33] conducted a meta-analysis of clinical trials of endothelin antagonists for aSAH and concluded that they reduce angiographic vasospasm and DIND, but on current evidence have no effect on outcome, which is possibly partly explained by the increased incidence of hypotension and pulmonary complications. This adverse event profile highlighted the importance of careful attention to fluid, and monitoring to detect early lung complications and blood pressure changes. CONSCIOUS-2 and CONSCIOUS-3 therefore use patient management guidelines to provide a consistent and standardized level of care across all study sites. The guidelines are consistent with those recommended by the Stroke Council of the American Heart Association [7] and focus on maintaining a euvolemic state, avoiding fluid overload, and treating DIND primarily with induced hypertension. There are also specific recommendations for prevention, detection and management of lung complications, monitoring of rescue therapy, and general patient care. On the basis of these guidelines, CONSCIOUS-3 includes an additional assessment of the $15 \mathrm{mg}$ dose, allowing investigators to explore whether there is a greater efficacy/safety ratio for coiled patients than the $5 \mathrm{mg} / \mathrm{h}$ dose assessed in CONSCIOUS-2. 
Statistical considerations and analysis

The incidence of vasospasm-related morbidity and all-cause mortality in placebo patients was initially estimated as $40 \%$ and $35 \%$ in CONSCIOUS-2 and CONSCIOUS-3, respectively based on CONSCIOUS-1 data. The placebo event rate was subsequently amended to $30 \%$ in CONSCIOUS-2 based on the observed blinded overall (placebo and clazosentan patients pooled) event rate in CONSCIOUS-2. The estimation of the placebo event rate in CONSCIOUS-3 may be amended and sample size revised in the future based on the real observed placebo event rate in CONSCIOUS-2. The sample size estimates of both studies were based on a relative risk reduction of $30 \%$ for the primary endpoint. The treatment effect will be tested by means of logistic regression adjusting for WFNS (I, II, >II). The Wald chisquare test will be used to determine the treatment effect. The primary analysis will be performed on the all-treated patient set. Dichotomous variables will be described using incidence and relative risk reduction of the active group(s) relative to placebo, with corresponding 95\% confidence intervals. GOSE will be categorized into poor outcome (score $\leq 4$ ) and good outcome (score > 4) and analyzed using the same statistical methods as for the primary endpoint. In both studies, the association between GOSE (dichotomized) and categorized total infarct volume, presence or absence of new cerebral infarcts due to vasospasm, as well as GOSE (dichotomized) and DIND (presence, absence) will be explored by means of chi-square statistics. Comparability of baseline demographics within each study will be considered on the basis of descriptive statistics, with relevant past or present concomitant diseases coded using MedDRA ${ }^{\mathrm{TM}}$.

\section{Conclusion}

New strategies for vasospasm prevention are needed to improve outcome after aSAH. CONSCIOUS-2 and CONSCIOUS-3 are large, multinational studies to investigate the efficacy and safety of clazosentan, an endothelin receptor antagonist, in the prevention of 
vasospasm-related adverse outcome after aSAH. The designs of these studies were based on experience from CONSCIOUS-1 (Table 3). When designing these studies, key considerations were: selection of primary endpoint; drug dose; possible differences in incidence of angiographic vasospasm in patients undergoing clipping or coiling; minimizing inclusion of patients unlikely to benefit from drug treatment; assessment of the radiology and clinical endpoints; and avoiding medical complications of treatment. These studies recruit a well defined population enriched for risk of vasospasm and use a centralized critical events committee to ensure consistency in data interpretation. It is hoped that these trials will facilitate a move towards more uniform and evidence-based management after aSAH.

\section{Acknowledgments}

The authors would like to thank Dr Jo Oswald, Dr Charlotte Mulcare and Dr Catherine Jones of Watermeadow Medical for medical writing (JO, CM) and editorial assistance (CJ), which was supported by Actelion Pharmaceuticals Ltd.

\section{Disclosures}

R.L. Macdonald receives grant support from the Physicians Services Incorporated Foundation, is a stock holder of Edge Therapeutics, Inc., and a consultant for Actelion Pharmaceuticals Ltd; N. Kassell is a consultant for Actelion Pharmaceuticals Ltd and Edge Therapeutics; S. Mayer is a consultant for Actelion Pharmaceuticals Ltd and Edge Therapeutics; E. Keller is a consultant for Actelion Pharmaceuticals Ltd, Roche Diagnostics, Philips and stockholder in NeMoDevices; A. Raabe is a consultant for Actelion Pharmaceuticals Ltd, BrainLAB and Carl Zeiss; R.Higashida is a consultant for Actelion Pharmaceuticals Ltd; P. Vajkoczy is a consultant for Aesculap, Actelion Pharmaceuticals Ltd, Roche, Essex, and ELANA; A. Molyneux is a consultant for Actelion Pharmaceuticals 
Ltd. He is also a consultant for and stockholder in Micrus Endovascular Inc (and has also received presentation support); I. Wanke is a consultant for Actelion Pharmaceuticals Ltd, Boston Scientific, ev3, and BALT, and receives a departmental grant from Boston; A. Frey, A. Marr and S. Roux are employees and stock holders of Actelion Pharmaceuticals Ltd. 


\section{References}

1. Lovelock CE, Rinkel GJ, Rothwell PM. Time trends in outcome of subarachnoid hemorrhage: population-based study and systematic review. Neurology 2010; 74: 14941501.

2. Hackett ML, Anderson CS. Health outcomes 1 year after subarachnoid hemorrhage. An international population-based study. Neurology 2000; 55: 658-662.

3. Mayer SA, Kreiter KT, Copeland D, et al. Global and domain-specific cognitive impairment and outcome after subarachnoid hemorrhage. Neurology 2002; 59: 1750-1758.

4. Kirkness CJ, Thompson JM, Ricker BA, et al. The impact of aneurysmal subarachnoid hemorrhage on functional outcome. J Neurosci Nurs 2002; 34: 134-141.

5. Macdonald RL, Pluta MR, Zhang JH. Cerebral vasospasm after subarachnoid hemorrhage: the emerging revolution. Nat Clin Pract Neurol 2007; 3: 256-263.

6. Crowley RW, Medel R, Kassell NF, Dumont AS. New insights into the causes and therapy of cerebral vasospasm following subarachnoid hemorrhage. Drug Discov Today 2008; 13 : 254-260.

7. Bederson JB, Connolly ES Jr, Batjer HH, et al. Guidelines for the management of aneurysmal subarachnoid hemorrhage. A statement for healthcare professionals from a special writing group of the Stroke Council, American Heart Association. Stroke 2009; 40: 994-1025. Erratum in Stroke 2009; 4(7): e518.

8. Dorhout Mees S, Rinkel GJE, Feigin VL, et al.; on behalf of the Cochrane Collaboration. Calcium antagonists for aneurysmal subarachnoid haemorrhage (Review). Cochrane Database Syst Rev 2007; 3: CD000277. 
9. Egge A, Waterloo K, Sjøholm H, Solberg T, Ingebrigsten T, Romner B. Prophylactic hyperdynamic postoperative fluid therapy after aneurysmal subarachnoid hemorrhage: a clinical, prospective, randomized, controlled study. Neurosurgery 2001; 49: 593-606.

10. Lennihan L, Mayer SA, Fink ME, et al. Effect of hypervolemic therapy on cerebral blood flow after subarachnoid hemorrhage: a randomized controlled trial. Stroke 2000; 31 : 383391.

11. Rabenstein AA, Lanzino G, Wijdicks EFM. Multidisciplinary management and emerging therapeutic strategies in aneurysmal subarachnoid haemorrhage. Lancet Neurol 2010; 9: 504-519.

12. Zhao J, Zhou D, Guo J, et al. Effect of fasudil hydrochloride, a protein kinase inhibitor on cerebral vasospasm and delayed cerebral ischemic symptoms after aneurysmal subarachnoid hemorrhage. Neurol Med Chir (Tokyo) 2006; 46: 421-428.

13. Vajkoczy P, Meyer B, Weidauer S, et al. Clazosentan (AXV-034343), a selective endothelin A receptor antagonist, in the prevention of cerebral vasospasm following severe aneurysmal subarachnoid hemorrhage: results of a randomized, double-blind, placebocontrolled, multicenter Phase 2a study. J Neurosurg 2005; 103: 9-17.

14. Macdonald RL. Clazosentan: an endothelin receptor antagonist for treatment of vasospasm after subarachnoid hemorrhage. Expert Opin Investig Drugs 2008; 17: 17611767.

15. Macdonald RL, Kassell NF, Mayer S, et al.; on behalf of the CONSCIOUS-1 Investigators. Clazosentan to Overcome Neurological Ischemia and Infarction Occurring After Subarachnoid Hemorrhage (CONSCIOUS-1): randomized, double-blind, placebocontrolled phase 2 dose-finding trial. Stroke 2008; 39: 3015-3021. 
16. Vergouwen MD. Effect of endothelin-receptor antagonists on delayed cerebral ischemia after aneurysmal subarachnoid hemorrhage remains unclear. Stroke 2009; 40: e714.

17. Millikan $\mathrm{CH}$. Cerebral vasospasm and ruptured intracranial aneurysm. Arch Neurol 1975; 32: $433-449$.

18. Dumont AS, Crowley W, Monteith SJ, llodigwe D, Kassell NF, Macdonald RL.

Endovascular treatment or neurosurgical clipping of ruptured intracranial aneurysms: effect on angiographic vasospasm, delayed ischemic neurological deficit, cerebral infarction and clinical outcome. Stroke 2010; in press.

19. Wilson JT, Pettigrew LE, Teasdale GM. Structured interviews for the Glasgow Outcome Scale and the extended Glasgow Outcome Scale: guidelines for their use. J Neurotrauma 1998; 15: 573-585.

20. Wilson JT, Pettigrew LE, Teasdale GM. Emotional and cognitive consequences of head injury in relation to the Glasgow Outcome Scale. J Neurol Neurosurg Psychiatry 2000; 69: 204-209.

21. van Swieten JC, Koudstaal PJ, Visser MC, Schouten HJ, van Gijn J. Interobserver agreement for the assessment of handicap in stroke patients. Stroke 1988; 19: 604-607.

22. Farrell B, Godwin J, Richards S, Warlow C. The United Kingdom transient ischaemic attack (UK-TIA) aspirin trial: final results. J Neurol Neurosurg Psychiatry 1991; 54: 10441054.

23. Brandt JSM, Folstein M. The telephone interview for cognitive status. Neuropsych Neuropsychol Behavior Neurol. 1988; 1: 111-117.

24. Food and Drug Administration clinical/medical guidelines. Available at: http://www.fda.gov/Drugs/GuidanceComplianceRegulatorylnformation/Guidances/ucm06498 1.htm (accessed 5 August, 2010). 
25. Pickard JD, Murray GD, Illingworth R, et al. Effect of oral nimodipine on cerebral infarction and outcome after subarachnoid haemorrhage: British aneurysm nimodipine trial. BMJ 1989; 298: 636-642.

26. Rosengart AJ, Schultheiss KE, Tolentino J, Macdonald RL. Prognostic factors for outcome in patients with aneurysmal subarachnoid hemorrhage. Stroke 2007; 38: 23152321.

27. Fergusen S, Macdonald RL. Predictors of cerebral infarction in patients with aneurysmal subarachnoid hemorrhage. Neurosurgery 2007; 60: 658-667, discussion 667.

28. Weidauer S, Lanfermann H, Raabe A, Zanella F, Seifert V, Beck J. Impairment of cerebral perfusion and infarct patterns attributable to vasospasm after aneurysmal subarachnoid hemorrhage. Stroke 2007; 38: 1831-1836.

29. Dankbaar JW, Rijsdijk M, van der Schaaf IC, Velthuis BK, Wermer MJ, Rinkel GJ. Relationship between vasospasm, cerebral perfusion, and delayed cerebral ischemia after aneurysmal subarachnoid hemorrhage. Neuroradiology 2009; 51: 813-819.

30. Kreiter KT, Mayer SA, Howard G, et al. Sample size estimates for clinical trials of vasospasm in subarachnoid hemorrhage. Stroke 2009; 40: 2362-2367.

31. Quinn TJ, Dawson J, Walters MR, Lees KR. Variability in modified Rankin scoring across a large cohort of international observers. Stroke 2008; 39: 2975-2979.

32. Jongbloed L. Prediction of function after stroke: a critical review. Stroke 1986; 17: 765776.

33. Kramer A, Fletcher J. Do endothelin-receptor antagonists prevent delayed neurological deficits and poor outcomes after aneurysmal subarachnoid hemorrhage?: a meta-analysis. Stroke 2009; 40: 3403-3406. 
Table 1. Study endpoints

\begin{tabular}{|c|c|}
\hline Primary endpoint & Secondary endpoints \\
\hline $\begin{array}{l}\text { Composite endpoint of at least one of: } \\
\text { - Death (any cause) } \\
\text { - New cerebral infarct(s) due to cerebral } \\
\text { vasospasm as either the primary or } \\
\text { relevant contributing cause, or not } \\
\text { adjudicated to be entirely due to causes } \\
\text { other than vasospasm } \\
\text { Delayed ischemic neurological deficit due } \\
\text { to cerebral vasospasm as either the } \\
\text { primary or relevant contributing cause, or } \\
\text { not adjudicated to be entirely due to } \\
\text { causes other than vasospasm } \\
\text { Neurological signs or symptoms } \\
\text { (depending on state of consciousness) in } \\
\text { the presence of confirmed cerebral } \\
\text { vasospasm on angiography (digital } \\
\text { subtraction angiography [DSA] or } \\
\text { valid rescue therapy }\end{array}$ & $\begin{array}{l}\text { - Functional outcome using the Glasgow } \\
\text { Outcome Scale (extended version, } \\
\text { dichotomized into good }(>4 \text { ) or poor }(\leq 4) \\
\text { - Total volume of new cerebral infarcts of all } 12 \\
\text { etiologies at Week } 6 \text { post-hemorrhage } \\
\text { Occurrence of death and the individual } \\
\text { morbidity components of the composite } \\
\text { primary endpoint }\end{array}$ \\
\hline
\end{tabular}


Table 2. mGCS and abbreviated NIHSS (as used in DIND assessment)

\begin{tabular}{|c|c|c|c|}
\hline \multicolumn{2}{|l|}{ mGCS } & \multicolumn{2}{|c|}{ abbreviated NIHSS } \\
\hline Test & Response options & Test & Response options \\
\hline $\begin{array}{l}\text { Eye } \\
\text { Opening }\end{array}$ & $\begin{array}{l}\text { 1. No response } \\
\text { 2. Response to pain } \\
\text { 3. Response to voice } \\
\text { 4. Spontaneous response }\end{array}$ & $\begin{array}{l}\text { Facial } \\
\text { Palsy }\end{array}$ & $\begin{array}{l}\text { 0. Normal symmetrical } \\
\text { 1. Minor paralysis } \\
\text { 2. Partial paralysis } \\
\text { 3. Complete paralysis } \\
\text { (one or both sides) }\end{array}$ \\
\hline $\begin{array}{l}\text { Verbal } \\
\text { Response }\end{array}$ & $\begin{array}{l}\text { 1. No response } \\
\text { 2. Incomprehensible words } \\
\text { 3. Inappropriate words } \\
\text { 4. Disoriented } \\
\text { 5. Oriented }\end{array}$ & $\begin{array}{l}\text { Motor } \\
\text { Arm }\end{array}$ & $\begin{array}{l}\text { 0. No drift } \\
\text { 1. Drift } \\
\text { 2. Some effort against gravity } \\
\text { 3. No effort against gravity } \\
\text { 4. No movement } \\
\text { 9. Amputation, joint fusion } \\
\text { 5a. Left arm } \\
\text { 5b.Right arm }\end{array}$ \\
\hline $\begin{array}{l}\text { Motor } \\
\text { Response } \\
\text { Left arm } \\
\text { Right arm }\end{array}$ & $\begin{array}{l}\text { 1. No response } \\
\text { 2. Abnormal extension } \\
\text { 3. Abnormal flexion } \\
\text { 4. Withdrawal } \\
\text { 5. Localizes } \\
\text { 6. Follows commands }\end{array}$ & $\begin{array}{l}\text { Motor } \\
\text { Leg }\end{array}$ & $\begin{array}{l}\text { 0. No drift } \\
\text { 1. Drift } \\
\text { 2. Some effort against gravity } \\
\text { 3. No effort against gravity } \\
\text { 4. No movement } \\
\text { 9. Amputation, joint fusion } \\
\text { 6a.Left leg } \\
\text { 6b.Right leg }\end{array}$ \\
\hline The modifi & score = eye opening respor & Tota & = facial palsy + left arm + right \\
\hline
\end{tabular}


+ verbal response + worst motor response

arm + left leg + right leg

DIND: delayed ischemic neurological deficit; mGCS: modified Glasgow Coma Scale; NIHSS:

National Institutes of Health Stroke Scale. 
Table 3. Comparison of key features of the CONSCIOUS studies

\begin{tabular}{|c|c|c|c|}
\hline & CONSCIOUS-1 & CONSCIOUS-2 & CONSCIOUS-3 \\
\hline $\mathbf{N}$ & 413 & 1157 & $>1400$ \\
\hline Securing procedure & Clip or coil & Clip & Coil \\
\hline Clot type (from CT & & & \\
\hline scan) & No & No & No \\
\hline local thin & Yes & Yes & No \\
\hline diffuse thin & Yes & No & Yes \\
\hline $\begin{array}{l}\text { local thick } \\
\text { diffuse thick }\end{array}$ & Yes & Yes & Yes \\
\hline Randomization & $\begin{array}{l}\text { Before or after } \\
\text { aneurysm } \\
\text { securing }\end{array}$ & $\begin{array}{l}\text { After aneurysm } \\
\text { securing }\end{array}$ & $\begin{array}{l}\text { After aneurysm } \\
\text { securing }\end{array}$ \\
\hline Clazosentan doses & 1,5 and $15 \mathrm{mg} / \mathrm{h}$ & $5 \mathrm{mg} / \mathrm{h}$ & 5 and $15 \mathrm{mg} / \mathrm{h}$ \\
\hline $\begin{array}{l}\text { Centralized } \\
\text { Critical Event } \\
\text { Committee }\end{array}$ & $\mathrm{No}^{*}$ & Yes & Yes \\
\hline $\begin{array}{l}\text { Patient management } \\
\text { guidelines }\end{array}$ & No & Yes & Yes \\
\hline Primary endpoint & $\begin{array}{l}\text { Angiographic } \\
\text { vasospasm }\end{array}$ & $\begin{array}{l}\text { Vasospasm- } \\
\text { related morbidity } \\
\text { and all-cause } \\
\text { mortality }\end{array}$ & $\begin{array}{l}\text { Vasospasm- } \\
\text { related morbidity } \\
\text { and all-cause } \\
\text { mortality }\end{array}$ \\
\hline
\end{tabular}




\begin{tabular}{|l|l|l|l|}
\hline Main secondary & Vasospasm- & GOSE & GOSE \\
endpoints & related morbidity & & \\
& and mortality; & & \\
& GOSE & & \\
\hline
\end{tabular}

${ }^{*}$ Central radiology review was performed (CT scans and angiograms). CT: computed tomography; GOSE: Glasgow Outcome Scale. 
Figure 1: Study design. aSAH: aneurysmal subarachnoid hemorrhage; CT: computed tomography; GOSE: Glasgow Outcome Scale (extended); mRS: modified Rankin scale; TICS: Telephone Interview for Cognitive Status.

CONSCIOUS-2: study design

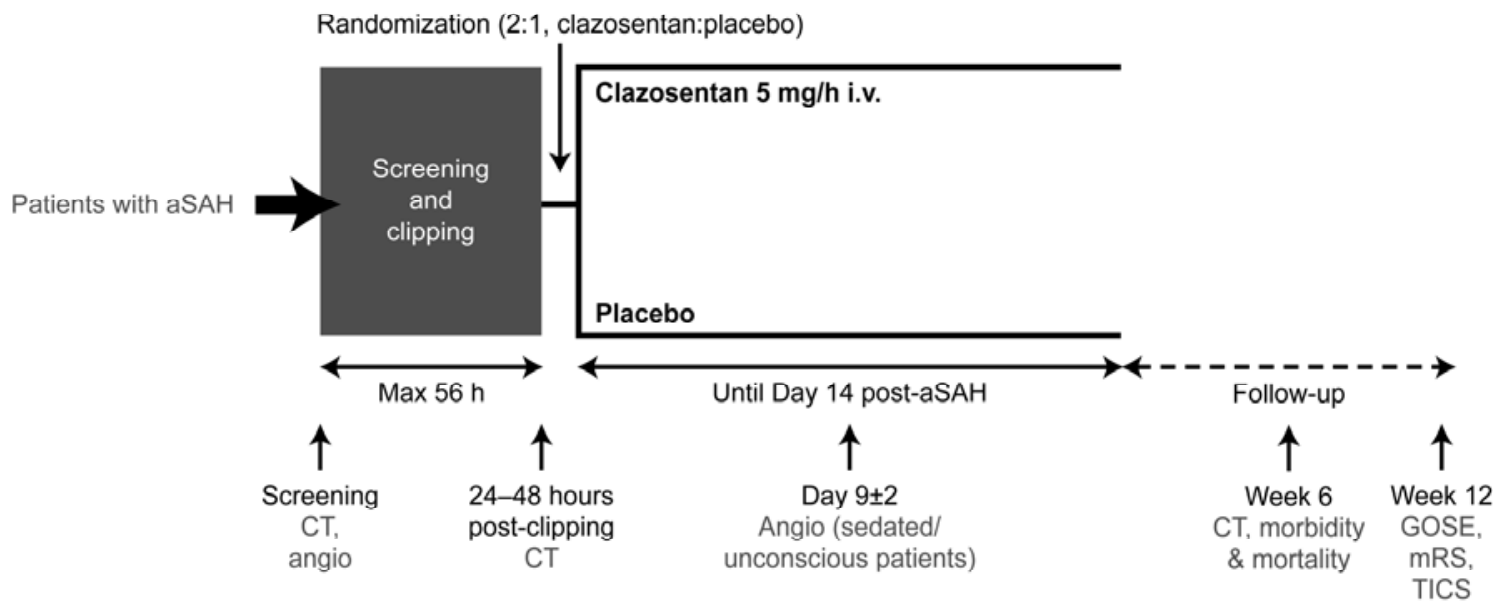

CONSCIOUS-3: study design

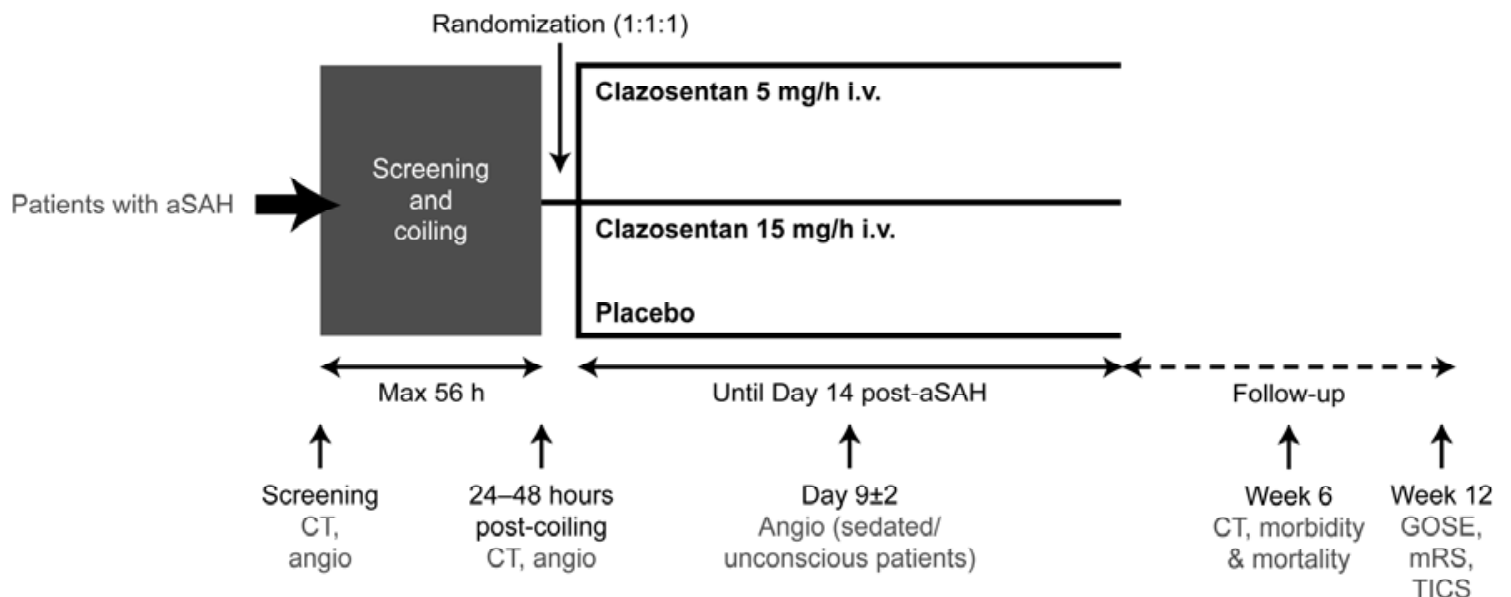


Figure 2: Endpoint data from CONSCIOUS-1 (all-treated set) as assessed by investigators (grey boxes) compared with central assessment (black boxes). A, Occurrence of moderate to severe angiographic vasospasm; $B$, Composite endpoint; C-E, Individual morbidity elements of the composite endpoint. All morbidity and mortality endpoints are within 6 weeks of aneurysm rupture. DIND: delayed ischemic neurological deficit. 


\section{A Moderate or severe vasospasm (up to 14 days)}

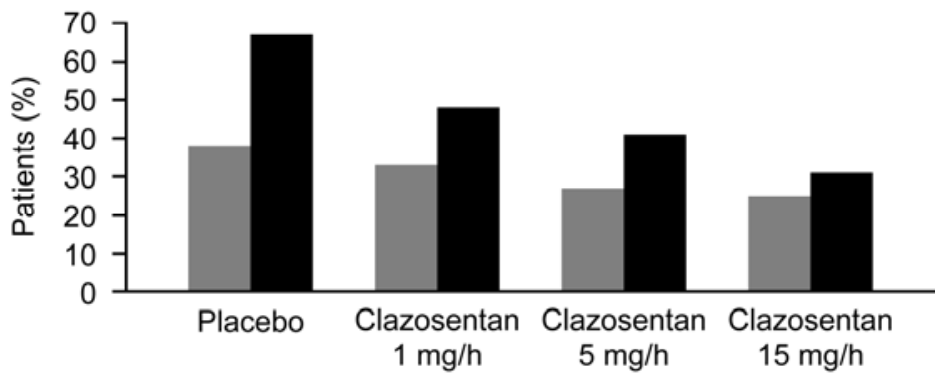

B Combined morbidity/mortality endpoint

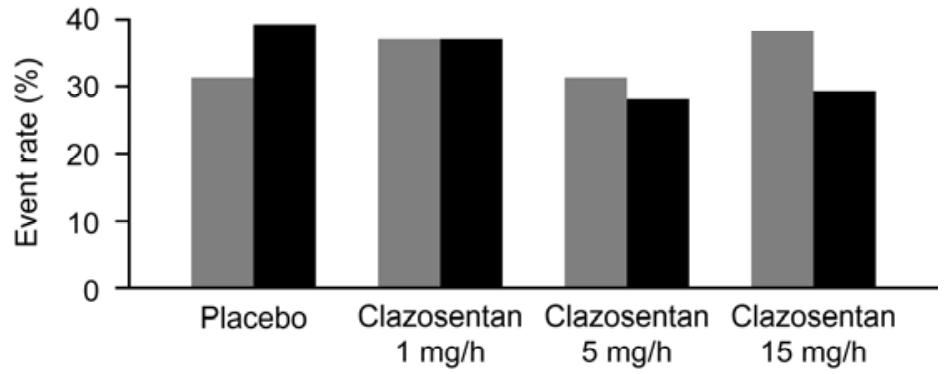

C New infarct (up to Week 6)

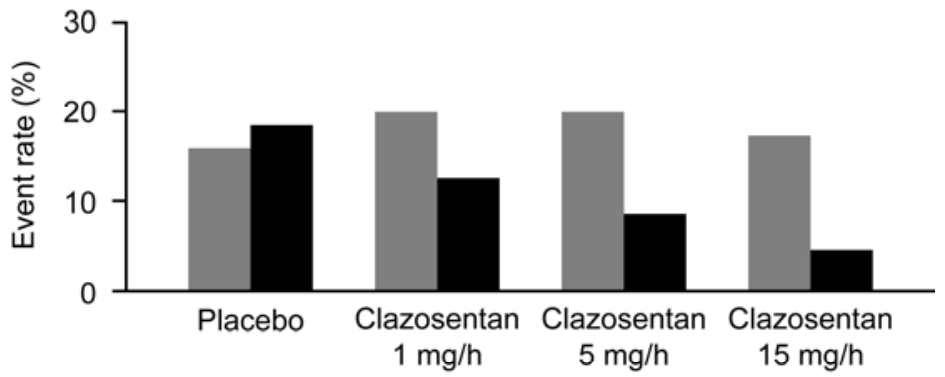

D DIND due to vasospasm (up to Week 6)

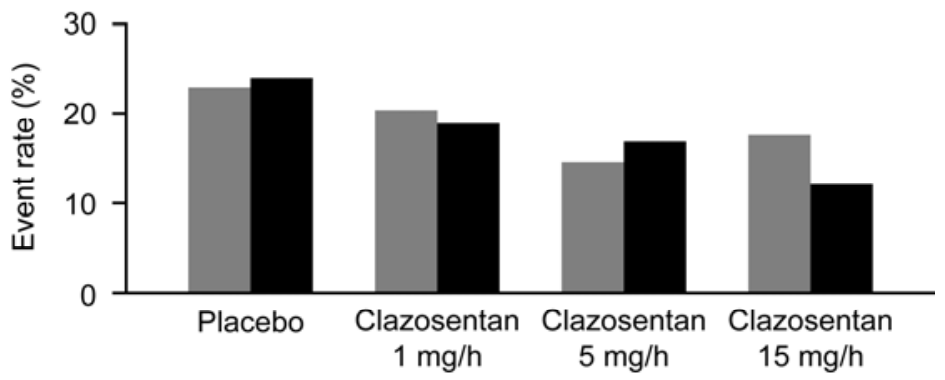

E Rescue therapy for vasospasm

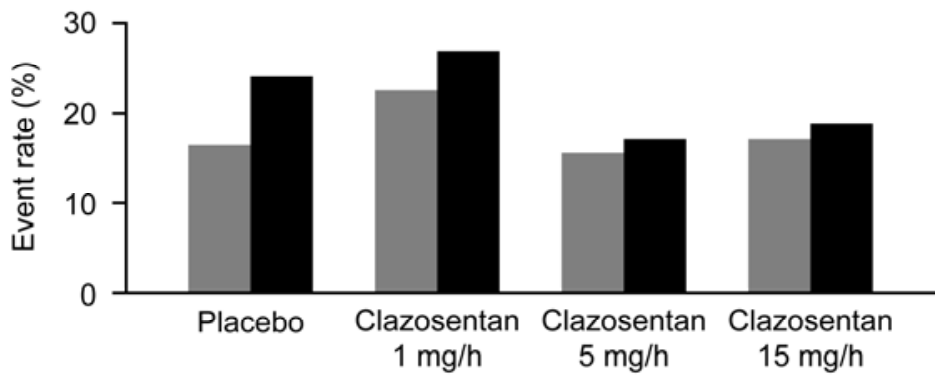

Investigator $\square$ Central 